\title{
Evaluating interactive digital television applications through usability heuristics
}

\author{
Evaluando aplicaciones de televisión digital interactiva a través \\ de heurísticas de usabilidad
}

\author{
Andrés Solano ${ }^{1} \quad$ Cristian Rusu $^{2} \quad$ César A. Collazos $^{1} \quad$ José Arciniegas $^{3}$
}

Recibido 8 de septiembre de 2011, aceptado 3 de enero de 2012

Received: September 8, 2011 Accepted: January 3, 2012

\begin{abstract}
RESUMEN
La Televisión Digital Interactiva (TDi) es considerada como la convergencia de la televisión y las tecnologías de la computación. La evaluación de usabilidad para aplicaciones basadas en tecnologías emergentes trae nuevos retos. La principal característica de la TDi es que los usuarios pueden interactuar con las aplicaciones; de esta manera la usabilidad es el principal aspecto a considerar cuando se diseñan aplicaciones de TDi. Las investigaciones actuales normalmente están enfocadas sobre las aplicaciones de TDi desde un punto de vista técnico, y no desde un enfoque centrado en el usuario. Hay una necesidad de nuevos métodos de evaluación de usabilidad o, por lo menos, utilizar de nuevas formas los métodos de evaluación existentes. Un conjunto de heurísticas de usabilidad específicas ha sido definido y validado, con el objetivo de ayudar en la evaluación de usabilidad de aplicaciones de TDi. También se ha propuesto una lista de verificación para ser usada al momento de aplicar las heurísticas de usabilidad.
\end{abstract}

Palabras clave: Televisión digital interactiva, aplicaciones, usabilidad, heurísticas, lista de verificación.

\begin{abstract}
Interactive Digital Television (iDT) is considered as the convergence of television and computer technologies. Usability evaluation for applications based on emerging information technology brings new challenges. The main iDT feature is that the user may interact with the application; therefore usability should be a main concern when designing iDT applications. Current research usually focuses on iDT applications from a technical point of view, rather than a user-centered approach. There is a need for new usability evaluation methods or at least for the use of traditional evaluations in novel ways. A set of specific usability heuristics was defined and validated, in order to help the usability evaluations of iDT applications. A usability checklist to be used when applying iDT heuristics is also proposed.
\end{abstract}

Keywords: Interactive digital television, applications, usability, heuristics, checklist.

\section{INTRODUCTION}

Interactive Digital Television (iDT) is considered as the link of television and computer technologies, which gather three typical features: interactivity, customization and digitization [1]. A TV program refers to "any type of content, should it be an advertisement, a movie, a quiz show, teletext page, email message or even any kind of sound" [2]. In iDT the program content, form or even the presentation

1 Departamento de Sistemas. Universidad del Cauca. Carrera 3 \#3N-100, Sector Tulcán. Teléfono (57)+2+8209800, ext. 2133. Popayán, Colombia. E-mail: afsolano@unicauca.edu.co; ccollazo@unicauca.edu.co

2 Escuela de Ingeniería Informática. Pontificia Universidad Católica de Valparaíso. Av. Brasil No. 2241. Teléfono (56)+32+2274096. Valparaíso, Chile. E-mail: cristian.rusu@ucv.cl

3 Departamento de Telemática. Universidad del Cauca. Carrera 3 \#3N-100, Sector Tulcán. Teléfono (57)+2+8209800, ext. 2114. Popayán, Colombia. E-mail: jlarci@unicauca.edu.co 
order, can be changed by the user. In addition, the user has access to interactive applications that can be independent or closely related to the subject or the progress of the content.

The iDT exceeds the analog TV in several aspects: capacity, better use of the spectrum, greater immunity to noise and interference, better sound and picture quality, potential for transmission of data simultaneously, saving power transmission. However, the main iDT advantage is that the user may interact with the application [2]. Interactivity allows the user to be an active part of the TV schedule, providing the ability to access or extend the information presented, to participate in forums and to control the sequence of information presented [3].

The usability evaluation of a software system is one of the most important stages in the user-centered design approach. It allows obtaining the usability characteristics of a software system and the extent to which de usability attributes, usability paradigms and usability principles are being implemented [4].

Usability evaluation for applications based on emerging information technology brings new challenges; however some questions arise, is it the classical concept of usability still valid? Which are the dimensions of the (new) usability? How can it be measured? How should we develop for (better) usability? There is a need for new evaluation methods or at least for the use of traditional evaluations in novel ways [5].

The ISO/IEC 9241 standard defines the usability as "the extent to which a product can be used by specified users to achieve specified goals with effectiveness, efficiency and satisfaction in a specified context of use" [6]. Take into account this definition, in the context of iDT applications, usability can be defined as: the extent to which specific users can access an application of interest and interact with the options that it offers for their entertainment, information or other, with minimal effort, quick and pleasant, in a given context of use.

Usability evaluation methods are commonly divided into inspection and testing methods. Inspection methods find usability problems based on the expertise of usability professionals. Testing methods find usability problems through the observation of the users while they use (and comment on) a system interface. Usability evaluation is needed particularly if the design concept is new. Users look for more than just a usable product; they look for a pleasing and engaging experience [7]. Therefore, usability should be a main concern when designing interactive iDT applications. Current research usually focuses on iDT applications from a technical point of view, rather than a user-centered approach. There is a necessity to establish methodologies that could lead to applications with a high level of usability. Such methodologies have to include accurate usability evaluations.

Heuristic evaluation is a widely used inspection method [8-9]. A group of evaluators (usually from three to five) inspect the interface design based on a set of usability heuristics. In order to ensure independent and unbiased evaluations, the inspection is performed individually. After all individual evaluations have been completed, the evaluators are allowed to communicate and have their findings aggregated in a single list of usability problems. Later on, each evaluator assigns scores to each problem's severity and frequency (on a 0 to 4 scale, from minor/less frequent to major/more recurrent). Severity and frequency are summed in order to get problem's criticality. Problems are ranked based on their average severity, frequency and criticality. The usability evaluation report includes usability problems, solution proposals, as well as positive findings. Heuristic evaluation is easy to perform, cheap and able to find many usability problems (both major and minor problems). However, it may miss domain specific problems. That is why the use of appropriate heuristics is highly significant.

The present work focuses on usability evaluation of iDT applications using heuristic evaluations. A set of 14 specific usability heuristics has been proposed and validated. A usability checklist to be used when applying the iDT heuristics is also proposed. First section highlights the main characteristics of iDT applications. Second section presents the methodology that has been used in heuristics development. The iDT usability heuristics proposal is presented in third section. Fourth section presents the results obtained in the heuristics evaluations, later, the fifth section presents the usability checklist for iDT applications. Sixth section presents preliminary conclusions and future works. 


\section{USABILITY IN IDT APPLICATIONS}

iDT includes relevant aspects such as: ease-of-use, entertainment, information, among others. Easeof-use is clearly a priority for design interactive applications. Many users are accustomed to using the TV in a passive way (channel changes only), so, the new paradigm consist in designing interactive applications more intuitive and clear as possible trying to get users to become active part of the TV schedule. In that sense, the user should be informed clearly of what can do in the application and how this can be done.

Users are accustomed to television entertains them; with the innovations of technology in the iDT applications increases the possibility of enhanced entertainment, because the users can interact with the programs that they are watching. In that sense, an interactive application too simple can be considered for the users as boring and uninteresting, for this reason it is important to focus on a pleasing appearance of the application and make it easy to learn and understand. Thus, other users may be attracted to use the different options and features of the application.

Usability will allow to users that use an iDT application to stay in it, enjoy the interaction, and have the desire to reuse in the future. To achieve this, iDT applications should be designed and implemented, so that all users can use and understand it without problems.

\section{iDT characteristics}

Nowadays the concept of television does not refer to a specific device, but rather a specific kind of content available almost everywhere, from the traditional TV set, to the computer, passing through the mobile phone or the screens, in taxis and throughout the city, freeing television from the TV set and bringing it out of the home. Additionally, current trends combine iDT with the web; users may navigate on internet from their TV sets, download and use applications, download content or customize the TV schedule of an enhanced form. It is expected that users can access to television and internet in a simple manner, from different devices.

iDT applications have a set of basic features that should be considered when evaluating their usability [10]:
- Interactivity: iDT applications should offer bidirectional communication, a fundamental requirement of any interactive system. An iDT application should invite user to participate, in order to have a more active experience while watching content. Interactivity is the ability to offer additional content to the television programs, allowing the user to view associated information with audiovisual content, to view the TV channels' schedule, to participate in contests, polls, to buy products or services, and even to participate in the television programs creation/customization.

- Customization: iDT applications should allow customization in terms of content, appearance and others, taking into account users' needs, skills, personal preferences, etc.

- Physical features of interaction: Human vision is optimal at a particular distance from the screen; therefore, iDT applications should take into account screen resolution and contrast. Traditionally, users watch TV in an environment that is oriented to relaxation and comfort. However, nowadays users can access this medium in various environments, from multiple devices (TV sets, phones, etc.) and using different technologies (high-definition, 3D, etc.).

- Consistency of applications and content: iDT applications should be related to the content itself, and relevant for specific users.

- Adaptability: iDT applications should be adaptable to different target public and environments. They should even suggest content/programs based on users' preferences and history of selection (among others).

\section{DEFINING USABILITY HEURISTICS FOR INTERACTIVE DIGITAL TELEVISION}

Usability inspections, including heuristic evaluation, are well documented and many publications describing the usage of the methods. Literature usually focuses on describing the advantages and disadvantages of usability evaluation methods but not on how to develop new methods and/or usability heuristics [10].

In order to develop usability heuristics for iDT applications, a specific methodology has been applied [11]. The methodology to establish new usability heuristics includes 6 stages: 
- STEP 1: An exploratory stage, to collect bibliography related to the main topics of the research: specific applications, their characteristics, general and/or related (if there are some) usability heuristics.

- STEP 2: A descriptive stage, to highlight the most important characteristics of the previously collected information, in order to formalize the main concepts associated with the research.

- STEP 3: A correlational stage, to identify the characteristics that the usability heuristics for specific applications should have, based on traditional heuristics and case studies analysis.

- STEP 4: An explicative stage, to formally specify the set of the proposed heuristics, using a standard template.

- STEP 5: A validation (experimental) stage, to check new heuristics against traditional heuristics by experiments, through heuristic evaluations performed on selected case studies, complemented by user tests.

- STEP 6: A refinement stage, based on the feedback from the validation stage.

An early version of the iDT usability heuristics were proposed in 2009 [12]. Later on, STEP 1 to STEP 4 of the methodology were performed, and a refined usability heuristic proposal was defined.

STEP 1 explored specific iDT applications and usability heuristics.

STEP 2 re-examined the meaning of the usability and its characteristics, in the context of iDT applications. As no specific and/or related iDT usability heuristics were founded, Nielsen's 10 [9] well know and extensively used heuristics were used at STEP 3. However, heuristic proposals for other fields, such as Social TV, Virtual Worlds and Grid Computing were also used.

The standard template used at STEP 4 was the following one:

- ID, Name and Definition: Heuristic's identifier, name and definition.

- Explanation: Heuristic's detailed explanation, including references to usability principles, typical usability problems, and related usability heuristics proposed by other authors.

- Examples: Examples of heuristic's violation and compliance.
- Benefits: Expected usability benefits, when the heuristic is accomplished.

- Problems: Anticipated problems of heuristic misunderstanding, when performing heuristic evaluations.

STEP 5 evaluated the set of iDT heuristics defined at STEP 4, against Nielsen's heuristics, in two cases studies. The applications were evaluated by two separate groups of evaluators, of similar experience, in equal conditions. One group used only the set of heuristics defined at STEP 4, while the other group used only Nielsen's heuristics. Usability problems founded by the two groups were then compared. Three categories of problems occurred:

- (P1) Problems identified by both groups of evaluators.

- (P2) Problems identified only by the group that used the set of heuristics defined at STEP 4.

- (P3) Problems identified only by the group that used Nielsen's heuristics.

As in both case studies (P2) included the highest percentage of identified problems, we may say that iDT heuristics worked better than Nielsen's heuristics. Question arises with problems (P3). Why these problems were not identified when using iDT heuristics? There are two possible reasons:

(1) iDT heuristics were not able to identify these problems, either because appropriate heuristics are missing, or because the heuristics are not properly specified.

(2) Evaluators using iDT heuristics subjectively ignored the problems.

Hypotheses (1) and (2) were checked by analyzing problems (P2) and (P3) and by complementary user tests. Hypothesis (2) proved to be the correct one. At STEP 6 the set of heuristics for iDT applications was refined, based on the results obtain at STEP 5.

\section{IDT USABILITY HEURISTICS}

A set of 14 iDT usability heuristics was specified, validated and refined. The 14 heuristics were grouped in three categories: (1) Design and Aesthetics, (2) Flexibility and Navigation and (3) Errors and Help. A summary of the proposed heuristics is presented below, including heuristic's ID, name, definition and explanation. 


\section{Design and Aesthetics Heuristics}

(H1) Match between the system and the real world: An iDT application should speak the user's language, with words, phrases and concepts familiar to the user. iDT applications should use specific conventions of the real world and should show the information in a natural order. The sequence of activities should follow user's mental processes. Metaphors should be easy to understand; there should be an intuitive mapping between controls and their functions.

(H2) Simplicity: An iDT application should not overload users with irrelevant and/or unnecessary information. Every extra unit of information competes with the relevant units of information and diminishes their relative visibility. iDT applications should show concise (but all necessary) information.

(H3) Consistency and standards: Design should be coherent and consistent throughout the iDT application; it should follow the norms or conventions for TV design in general, as well as for new specific elements of iDT. iDT applications should present similar elements in similar ways. Terminology, controls, graphics and menus should be consistent throughout the system; there should be a consistent look and feel for the system interface. As there are not yet widely recognized standards for iDT applications, highlights the importance of the consistency over standards.

(H4) Feedback: An iDT application should provide feedback to the user, at least when he/she is performing key actions. iDT applications should provide feedback on user's key actions, in a clear manner and within a reasonable time. User should be able to clearly identify their location into the application, and the available options.

(H5) Physical constraints: An iDT application's elements should be visible at the visual range of watching TV, and in various types of lighting. iDT applications design should consider issues related to the size, distances between elements displayed on screen, lighting, and others environmental factors. The concept of television is being redefined, television becomes ubiquitous; therefore specific factors should be considered.

(H6) Extraordinary users: An iDT application should be inclusive, attending (all) special users' needs.
iDT applications should at least use appropriately color restricted and provide alternative mechanisms for users with hearing problems.

\section{Flexibility and Navigation Heuristics}

(H7) Structure of information: An iDT application should organize information hierarchically, from general to specific. Related pieces of information should be clustered together; the amount of information should be minimized; option, titles and headlines should be straightforward, short and descriptive.

(H8) Navigation: An iDT application should allow simple navigation; user should easily move through the application and locate information of interest. iDT applications should provide navigational feedback (e.g. showing a user's current and initial states, where they have been, and what options they have for where to go) and navigational aids (e.g. find facilities).

(H9) Recognition rather than recall: The iDT application's main elements and options should be always kept available; user should not have to remember information from one screen to another. Help and instructions should be visible or easily accessible when needed; relationship between controls and their actions should be obvious; input formats and units of values should be indicated.

(H10) Flexibility and efficiency of use: An iDT application should allow a wide range of user expertise; it should allow users to personalize the application according to their skills; it should adapt to different environments. iDT applications should offer appropriate guide to novice users. Experienced users should get appropriate mechanism to customize applications according to their needs, skills, and personal preferences.

(H11) User control and freedom: An iDT application should offer users control over their actions and should allow free exploration. iDT applications provide "undo" (or "cancel") and "redo" options; exits should be clearly marked (when users find themselves somewhere unexpectedly); facilities to return to the top level should be provided, at all stages. Facilities to return to previous points and to the main screen should be provided, from anywhere in the application. Users should be able to freely explore the application, without castigation. 


\section{Errors and Help Heuristics}

(H12) Error prevention: An iDT application should provide appropriate mechanisms to prevent errors. iDT applications should provide appropriate messages in order to prevent users' errors. User confirmation should be required before carrying out a potentially "dangerous" action (e.g. deleting important information).

(H13) Recovering from errors: An iDT application should provide clear messages, hopefully indicating causes and solutions for errors. Error messages should adequately describe problems; they should assist in diagnosis and suggest ways of recovery in a constructive way; error messages should be written in a non-derisory tone and refrain from attributing blame to the user.

(H14) Help and documentation: An iDT application should provide users a clear and simple help, in their own language. iDT applications should offer clear, direct and simply help, expressed in user's idiom, free from jargon and buzzwords; help should be easy to search, understand and apply.

Table 1 present the mapping between iDT 14 heuristics and Nielsen's 10 heuristics. However, as the heuristics' specification shows, the proposal is not just a particularization of Nielsen's heuristics.

Table 1. Mapping between iDT heuristics and Nielsen's heuristics.

\begin{tabular}{|c|l|l|l|}
\hline \multicolumn{2}{|c|}{ iDT Heuristics } & \multicolumn{2}{c|}{ Nielsen's Heuristics } \\
\hline ID & \multicolumn{1}{|c|}{ Definition } & ID & \multicolumn{1}{|c|}{ Definition } \\
\hline H1 & $\begin{array}{l}\text { Match between } \\
\text { system and the } \\
\text { real world }\end{array}$ & N2 & $\begin{array}{l}\text { Match between } \\
\text { system and the } \\
\text { real world }\end{array}$ \\
\hline H2 & Simplicity & N8 & $\begin{array}{l}\text { Aesthetic and } \\
\text { minimalist design }\end{array}$ \\
\hline H3 & $\begin{array}{l}\text { Consistency and } \\
\text { standards }\end{array}$ & N4 & $\begin{array}{l}\text { Consistency and } \\
\text { standards }\end{array}$ \\
\hline H4 & $\begin{array}{l}\text { Feedback } \\
\text { H5 }\end{array}$ & $\begin{array}{l}\text { Physical } \\
\text { constraints }\end{array}$ & $\begin{array}{l}\text { Visibility of } \\
\text { system status }\end{array}$ \\
\hline H6 & $\begin{array}{l}\text { Extraordinary } \\
\text { users }\end{array}$ & N8 & $\begin{array}{l}\text { Aesthetic and } \\
\text { minimalist design }\end{array}$ \\
\hline H7 & $\begin{array}{l}\text { Structure of } \\
\text { information }\end{array}$ & N7 & $\begin{array}{l}\text { Flexibility and } \\
\text { efficiency of use }\end{array}$ \\
\hline
\end{tabular}

\begin{tabular}{|c|l|c|l|}
\hline \multicolumn{2}{|c|}{ iDT Heuristics } & \multicolumn{2}{c|}{ Nielsen's Heuristics } \\
\hline ID & \multicolumn{1}{|c|}{ Definition } & ID & \multicolumn{1}{|c|}{ Definition } \\
\hline H8 & Navigation & N3 & $\begin{array}{l}\text { User control and } \\
\text { freedom }\end{array}$ \\
\hline H9 & $\begin{array}{l}\text { Recognition } \\
\text { rather than recall }\end{array}$ & N6 & $\begin{array}{l}\text { Recognition rather } \\
\text { than recall }\end{array}$ \\
\hline H10 & $\begin{array}{l}\text { Flexibility and } \\
\text { efficiency of use }\end{array}$ & N7 & $\begin{array}{l}\text { Flexibility and } \\
\text { efficiency of use }\end{array}$ \\
\hline H11 & $\begin{array}{l}\text { User control and } \\
\text { freedom }\end{array}$ & N3 & $\begin{array}{l}\text { User control and } \\
\text { freedom }\end{array}$ \\
\hline H12 & Error prevention & N5 & Error prevention \\
\hline H13 & $\begin{array}{l}\text { Recovering from } \\
\text { errors }\end{array}$ & N9 & $\begin{array}{l}\text { Help users } \\
\text { recognize, } \\
\text { diagnose, and } \\
\text { recover from } \\
\text { errors }\end{array}$ \\
\hline H14 & $\begin{array}{l}\text { Help and } \\
\text { documentation }\end{array}$ & N10 & $\begin{array}{l}\text { Help and } \\
\text { documentation }\end{array}$ \\
\hline
\end{tabular}

Heuristics $\mathrm{H} 1, \mathrm{H} 3, \mathrm{H} 4$, and $\mathrm{H} 9$ particularize Nielsen's heuristics N2, N4, N1, and N6 (respectively), based on iDT applications' characteristics. Heuristics H12, H13 and H14 put Nielsen's heuristics N5, N9 and N10 (respectively) into the context of iDT applications. Heuristics $\mathrm{H} 2, \mathrm{H} 5$ and $\mathrm{H} 6$ particularize Nielsen's N8 heuristics. Heuristics H7 and H10 denote Nielsen's N7 heuristic. Heuristics H8 and H11 detail Nielsen's N3 heuristic.

\section{APPLYING IDT USABILITY HEURISTICS IN PRACTICE}

Heuristic evaluation was executed taking into account the following steps [8]:

STEP 1: Each evaluator works independently 1-2 hours inspecting the applications based on Nielsen's heuristics, recording the clearest way possible usability problem identified and grouped according to the usability principle that not correspond.

STEP 2: Once all reviewers have made the individual evaluation, they come together to create a single list of usability problems grouped according to the usability principle they found as a problem.

STEP 3: The list of usability problems obtained in the step 2, will be deliver to each evaluator to estimate the severity and frequency with which problems 
appear. The notes are grouped according to the severity and frequency scales presented in Table 2.

Table 2. Severity and Frequency scales.

\begin{tabular}{|c|c|c|}
\hline Note & Severity & Frequency \\
\hline 0 & Not a usability problem. & $<1 \%$ \\
\hline 1 & $\begin{array}{l}\text { "Cosmetic" problem: need } \\
\text { not be solved unless you have } \\
\text { extra time on the project. }\end{array}$ & $1-10 \%$ \\
\hline 2 & $\begin{array}{l}\text { Minor usability problem: low } \\
\text { priority fix. }\end{array}$ & $11-50 \%$ \\
\hline 3 & $\begin{array}{l}\text { Major usability problem: } \\
\text { important to fix it, should be } \\
\text { given high priority. }\end{array}$ & $51-90 \%$ \\
\hline 4 & $\begin{array}{l}\text { Catastrophic usability } \\
\text { problem: it is imperative to fix } \\
\text { before the product is release. }\end{array}$ & $>90 \%$ \\
\hline
\end{tabular}

STEP 4: Once all reviewers valuate the grade for each problem according to their severity and frequency of occurrence, the evaluation coordinator calculates the Criticality (Severity + Frequency) of each usability problem. Subsequently, the coordinator averaging the individual scores, calculate the standard deviation, does a ranking of the problems (as the average Severity, Frequency or Criticality), and analyzes the results.

\section{Experimentation}

Applications used for the case studies were developed in the iDT experimental laboratory of the University of Cauca - Colombia, under ST-CAV (T-Learning services to support a Virtual Academic Community - CAV) [13] project. The project aims to support a CAV in television from various scenarios, such as: Terrestrial Digital Television (TDT) on DVB [14] (Digital Video Broadcasting) standard, Mobile Television based on DVB-H and IPTV, so the project ST-CAV aims to support learning processes in television (T-Learning) through Web 2.0 services, seeking to support and facilitate learning and knowledge building around various topics within a CAV.

Considering that the iDT users can access a wide range of applications, which can be implemented for different environments such as TDT, IPTV ${ }^{4}$,

4 IPTV (Internet Protocol Television): System where a digital television service is delivered to its customers using IP over a network infrastructure.
Mobile $\mathrm{TV}^{5}$, among others [15], in this paper applications used were those that are transmitted using industry-standard DVB technology, which was adopted in Colombia by the National Television Commission [16] in 2008, and also follows the specification MHP (Multimedia Home Platform) [17]. The standard transmission has several modes of distribution: DVB-T, if the distribution is done through the air, DVB-C, if the distribution is done by Cable, however, the content and applications are not affected on the side the client for these modes of distribution.

The applications have a number of features that enable users to control and exchange information proactively through a bidirectional communication channel or back channel that let users interact with the object of transmission, whether video, images, audio or data [18]. Through iDT receiver (Set Top Box - STB), device that allows to adapt the digital signal, an integration and execution of the applications on television content is performed, but also a backchannel connection to a set applications and remote services that can be accessed are provided, based on the information that user want at any given time, or to the dynamic interaction system [19].

The proposed iDT usability heuristics were checked against Nielsen's 10 heuristics, using the iDT applications: Electronic Program Guide, Blog and Chat, as cases studies.

- The Electronic Program Guide or EPG (for its acronym in English Electronic Program Guide) provides information on the programs being broadcasted on a channel program, programs to be broadcasted in the day, programs to be broadcasted in the next few days a week, describing the programs, start and end time, duration, among others. The EPG provides information about the favorite and most viewed programs or who have obtained more votes in the polls. Users can add or remove programs from the list of favorites. The EPG can be accessed by a user pressing the blue button in an interactive way. Figure 1 shows the main menu interface of the EPG.

\footnotetext{
5 Mobile TV: System where a digital television service is delivered to its customers through a mobile device.
} 


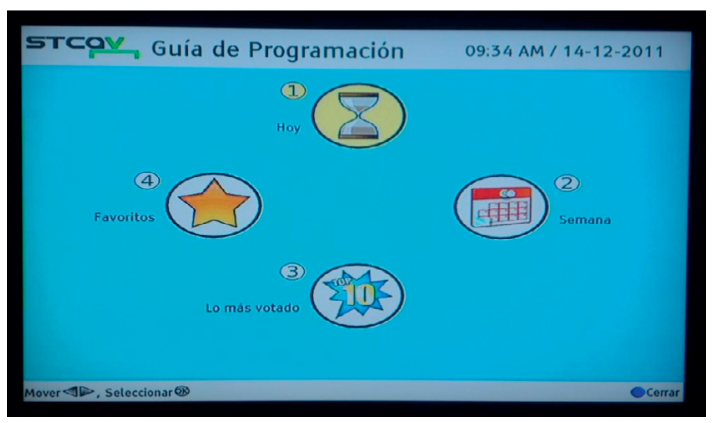

Figure 1. Main menu of the EPG.

- The Blog or mini-blog is an application that allows users to post messages or news to be consulted or discussed by members of the community. Figure 2 shows a list of messages posted to the blog.

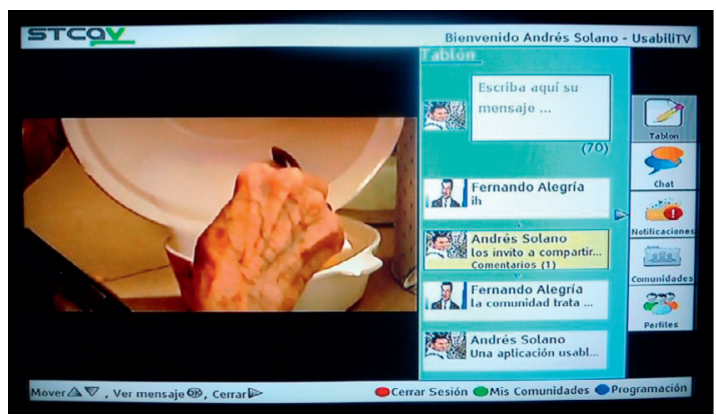

Figure 2. List of messages posted to the blog.

- Chat is an application that allows communication between users of the community. Figure 3 shows the conversation between users of the chat.

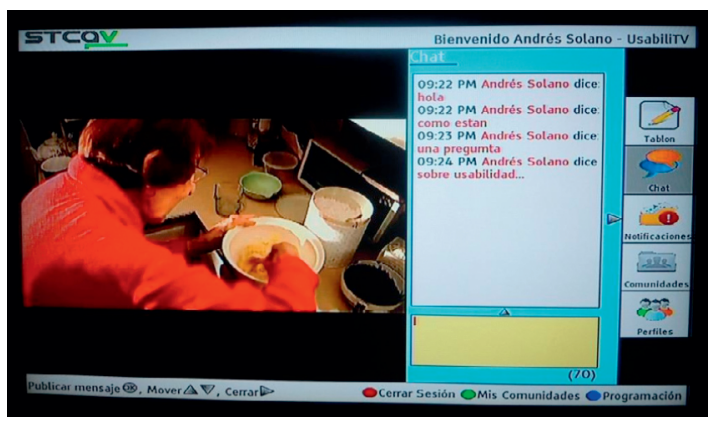

Figure 3. Conversation between users of the chat.

\section{Results of evaluations}

iDT applications: EPG, Blog y Chat, were examined by two groups of 5 evaluators. The 10 evaluators had similar (medium) experience on issues about usability (heuristic evaluations) and a medium/high experience on issues related to the management and development of iDT applications. The first group performed a heuristic evaluation of applications using only Nielsen's heuristic, while the second group performed a similar heuristic evaluation, but using only heuristics for iDT applications. Table 3 shows the number of usability problems identified by each group of evaluators in the heuristic evaluations.

Table 3. Usability problems identified in the applications.

\begin{tabular}{|c|c|c|c|}
\hline \multicolumn{2}{|c|}{$\begin{array}{c}\text { Group 1: Using } \\
\text { Nielsen's heuristics }\end{array}$} & \multicolumn{2}{c|}{$\begin{array}{c}\text { Group 2: Using iDT } \\
\text { heuristics }\end{array}$} \\
\hline ID & $\begin{array}{c}\text { Number of } \\
\text { problems }\end{array}$ & ID & $\begin{array}{c}\text { Number of } \\
\text { problems }\end{array}$ \\
\hline N1 & 3 & H4 & 3 \\
\hline N2 & 4 & H1 & 4 \\
\hline \multirow{2}{*}{ N3 } & 7 & H8 & 8 \\
\cline { 3 - 4 } & H11 & 4 \\
\hline N4 & 1 & H3 & 2 \\
\hline N5 & 1 & H12 & 2 \\
\hline N6 & 1 & H9 & 1 \\
\hline \multirow{2}{*}{ N7 } & 0 & H7 & 2 \\
\cline { 3 - 4 } & & H10 & 2 \\
\hline \multirow{2}{*}{ N8 } & 6 & H2 & 3 \\
\cline { 3 - 4 } & & H5 & 2 \\
\hline N9 & 0 & H6 & 2 \\
\hline N10 & 1 & H13 & 0 \\
\hline Total & 24 & Total & 3 \\
\hline
\end{tabular}

A total of 60 problems were identified by the 10 evaluators. More usability problems were captured using iDT heuristics, than using Nielsen's heuristics:

- (P1) 21 problems were identified by both groups of evaluators.

- (P2) 15 problems were identified only by the group that used iDT heuristics.

- (P3) 3 problems were identified only by the group that used Nielsen's heuristics.

The 3 usability problems identified using the Nielsen's heuristics (P3) were associated to heuristics N2-Match between system and the real world (1 problem), N3-User control and freedom (1 problem), and N8Aesthetic and minimalist design (1 problem). The set of iDT heuristics provides the tools that can potentially 
identify all these problems: H1-Match between the system and the real world, H8-Navigation and H11-User control and freedom, and H2-Simplicity, H5-Physical constraints and H6-Extraordinary users, respectively. Moreover, all (P3) usability problems were qualified with relatively low severity scores (severity value higher is 2,6 on a scale of 0 to 4 , the other 2 problems have notes of 2 and 2,4), and are not in the ranking of criticality. According to the above, the evaluators that used iDT heuristics subjectively ignored the 3 (minor) usability problems identified only Nielsen's heuristics.

A usability test was designed and it was performed with 5 representative users. The test was focused on the 3 usability problems identified only by Nielsen's heuristics. All these problems were tested to be perceived as minor problems or (not at all problems) by users.

Analyzing the 15 problems identified only heuristics by iDT heuristics (P2), most of them were qualified as critics: 9 of 15 problems had a criticality of 6 or superior, on a scale from 0 to 8 . Moreover, 11 of the 15 problems had a note of severity superior to 2.5 .

All these results seem to prove that iDT heuristics worked better than Nielsen's heuristics.

\section{APPLYING IDT USABILITY HEURISTICS IN PRACTICE}

Based on the experiments we have made, the nature of the usability problems identified when applying iDT heuristics, and the problems that some evaluators had when applying such heuristics, a usability checklist was defined. It details iDT heuristics and help their use in heuristic evaluation practice. The checklist is presented below.

(H1) Match between the system and the real world

- The purpose of the application is clear to users.

- The elements of the application (interface controls, instructions, etc.) use words, phrases and concepts familiar to user.

- Information on the elements of the application is presented in a simple form, natural and logical order.

- The application language is familiar to users.

- The activities sequence of the application follows the mental processes of users.
- The application uses metaphors and user interface controls that correspond with reality.

- The metaphors are easy to understand for users.

- Metaphors help users to better understand (the meanings of) the application.

- Metaphors are used only for simple concepts and/or tasks.

- Interface controls important are presented on the screen.

- The relationship between the interface controls and the real controls is intuitive.

- In the application each option or element is over-explained.

- In the application the complex elements are explained.

(H2) Simplicity

- The application interface is simple, not overloaded with information, options or other elements that distract the user.

- The alternatives that the user needs to perform a task are visible.

- The information presented in the application is simple, concise and clear.

- The elements that make up the application (interface controls, instructions, etc.) are clear and intuitive.

- The instructions are preferably in the bottom of the screen.

- There are abstract icons or graphic elements.

- The long-length text is divided into sections.

- There are elements in the application solely ornamental.

- In the application there are icons, controls, menus, graphics, text or other redundant elements.

(H3) Consistency and standards

- The same language and terminology is used in the elements that make up the application (interface controls, help, instructions, etc.).

- Interface controls that appear on different screens are used whenever the same way.

- Each screen that makes up the application has a consistent visual appearance.

- In similar situations are repeated sequences of actions.

- The design of the interface controls is consistent.

- The instructions, error messages, navigation menus, among others, appear in the same place of the screens that make up the application. 
- Interface controls that are repeated throughout the application have the same functionality and retain the same location.

- The size of the text (titles, subtitles, normal text or others) is consists in the screens that make up the application.

- Using more than two fonts on a screen of the application.

- The text of the application uses Tiresias font.

- The text has a minimum size of 18 points.

- Text length does not exceed 90 words on the screen.

- Text length does not exceed 45 words per quarter of the screen.

- The colors remain RGB values within a range of 16-240. That is, strong colors (e.g. red and orange) have low intensity and do not use pure black and white colors.

- The data entry forms maintain consistency.

- The results of the execution of the tasks are presented consistently.

(H4) Feedback

- The application provides clear indicators of their status.

- The transition from one state to another is readily apparent to users.

- The application clearly responds to user actions.

- The application clearly shows where the user is located.

- The application clearly shows the available options.

- Each screen that makes up the application displays your relationship with others.

- The application provides feedback to the user in a reasonable time.

- Response times of the application are appropriate to the mental processes of the users.

- The user is informed about the progress of a process.

- The user is informed if a process requires a long waiting time.

- There are clear indicators of the status of tasks.

- The application allows users to turn off warnings of feedback that are not considered necessary.

- A selected option is clearly visible on others.

(H5) Physical constraints

- The size of screen elements is proportional to the distance between them.

- The length and text size is proportional to the size of device interaction.
- The application text is displayed correctly in a range of distances from 3 to 5 meters.

- The display elements are displayed correctly in various types of lighting.

- In the application to avoid very light or very dark colors.

- The application uses dark text on a light background.

(H6) Extraordinary users

- The application used properly restrained colors (green and red, in the case of colorblind).

- The application provides alternative mechanisms for visually impaired users (using Braille keyboard, translation of text to speech, etc.).

- The application allows users to configure the display of colors restricted.

- The application provides alternative mechanisms for hearing impaired users (using subtitles or translation of the text to sign language).

- The application allows the configuration of alternative mechanisms for users with hearing problems.

(H7) Structure of information

- The structure of the elements on the screen is simple.

- The related information is grouped in the application.

- The information is organized hierarchically (e.g. from general to specific, by thematic, etc.).

- Related interface controls are grouped and organized.

- The application uses similar colors to group related elements.

- The application provides information search mechanisms.

- The elements on display are divided into L-shaped (L) inverted ("J").

- Application elements such as titles and logos are on the top left corner of the screen.

- Navigation options in the application are located preferably at the bottom of the screen.

- Lots of text supported by a video is located to the left of the video.

- Small amount of text supported by a video is located to the right of the video.

(H8) Navigation

- The application allows a simple navigation, clear and predictable. 
- It shows the user their location within the application, and basic navigation options.

- The application provides to users a natural way of return in each of the screens that comprise it.

- Each screen of the application that follows a sequence provides options to go to the main screen (home), the next and the previous screen.

- In the application there are options that do not lead anywhere.

- The application maintains a consistent and coherent navigation across the screens that comprise it.

- The application combines several methods of navigation (e.g. linear and trees, among others).

- The application clearly differentiates a selected option over others.

- A selected option helps the user to realize that can move to other options.

- The application provides menus that use the remote control buttons to directly select an option, without any navigation menu.

- The navigation design is based on the up/down, left/right and OK buttons.

- If a user reaches the end of the navigation area, pressing the down arrow moves the cursor to the initial position of navigation.

- In the application there is a clear and explicit sequence steps for completion of each task.

(H9) Recognition rather than recall

- The main interface controls, instructions, among others, are always available, visible and easily accessible.

- The application tells the user the data format and units of the values to enter.

- The options and / or functions are easy to find.

- The relationship between options and actions is obvious.

- The information fields completed by users are kept in memory.

(H10) Flexibility and efficiency of use

- The application offers quick navigation mechanisms, such as shortcuts to basic functionality of the application.

- The application is customizable according to the needs, characteristics, personal preferences, etc. of the users. The application offers users the ability to adjust the size, location, brightness, contrast, transparency, among other characteristics of the interface elements.
- The application allows users to return to the default configuration (or an earlier one) of the elements that comprise it.

- The application configuration is related to the device configuration.

- The application is readily available for connections at different speeds.

- The actions realized for the user take a long time.

- The application informs the user whether the execution of an action requires a long time.

- The application responds to the speed of navigation imposed by the user, based on their learning pace.

- The application offers the possibility of auto input for the user to minimize the time entering data.

- The application minimizes the use of heavy images (large size in bytes) that influence the time of application load.

- The application suggests programs to users based on their preferences, history of options selected, etc.

(H11) User control and freedom

- The application offers options to "undo" (or "cancel") and "redo" actions or tasks.

- Tasks canceled in the application immediately stop, providing a proper feedback.

- In the application users reverse their actions easily.

- The application allows the user to override an action in progress.

- In the application the output options are always available, visible and clearly marked.

- The application offers options for returning to a point just above and to return to the main screen (main) from anywhere.

- The application asks the user to confirm actions that will have drastic consequences, negative or destructive.

- The application offers the possibility of auto input to minimize the time entering data and the possibility of entering incorrect data.

- Users have the ability to reverse an application configuration easily.

- Users have the ability to easily switch between help and their activities.

- After agreeing to help, users can continue their activities from where they left broken. 
- The application is easy to control by the user, at any time the user has the ability to hide or quit the application, to view the program in full screen.

(H12) Error prevention

- The application provides easy to understand messages that prevent errors.

- The application notifies the user before perform an action that potentially "dangerous."

- The application provides selection methods to user (e.g. selecting elements from a list of options) as alternatives for data entry.

- The application allows user to predict possible errors.

- The application clearly indicates the type of data can be entered in a particular field.

- Input fields indicate the length of the data and values units.

- In the application the data entry fields contain default values where appropriate.

- The application validates all input.

- The application provides wizards for common tasks.

(H13) Recovering from errors

- Error messages are simple and describe the problem clearly.

- Error messages are written in a language familiar to the user.

- Error messages use a terminology and consistent design.

- The error messages suggest the cause of the problem that has caused.

- The error messages indicate what action the user must perform to correct the underlying problem.

- Error messages are written in a constructive way, so it does not attribute blame or insult the user.

- Error messages using violent or hostile words.

- The application uses appropriate sounds to indicate errors.

(H14) Help and documentation

- The application offers a clear and simple help.

- Help is expressed in the user's language, free of jargon and slang.

- In the application the help is easy to find, understand and apply.

- Help is always visible and available.
- The sections and information structure of the help are easily distinguished.

- The instructions of the help follow the actions sequence to realize by the user to achieve a task.

- The help interface is consistent with the application interfaces.

- The information is easy to find in the help.

- The information presented in the help is accurate, complete and understandable.

- The help describe correctly the options that offers the application.

- In the complex functionalities is offered help in that same place and time.

- In the application there is context-sensitive help that guides the user regarding the use of various existing elements.

\section{CONCLUSIONS AND FUTURE WORKS}

As iDT is nowadays a reality and the number and type of users is growing fast, the usability of iDT applications became a main issue. There is a need for new usability evaluation methods or at least usability evaluations should be particularized for iDT environments.

A set of 14 specific usability heuristics and an associated usability checklist were developed. The new heuristics were validated through the heuristic evaluation of three iDT applications. As no specific iDT usability heuristics were found, the proposal is based on the well-known and widely used Nielsen's 10 heuristics as well as on heuristic proposals for other fields (such as Social TV, Virtual Worlds and Grid Computing). However, as the heuristics' specification shows, the proposal is not just a particularization of Nielsen's heuristics; the set of 14 usability heuristics was specifically designed for iDT applications.

To make the experience a user with an iDT application to be successful and as convincing as possible, it is desirable to develop usable applications. The 14 heuristics proposed aims to contribute to the usability of the iDT applications in order to ensure the best interactive experience for the user; the checklist also seeks to contribute to this purpose.

Designers and/or developers of iDT applications need to learn design principles in order to create 
highly usable applications. Taking into account the perspective of users, usability can make the difference between developing a task completely or not, and enjoy the process or frustrated, so the proposed heuristics try to greatly increase the chance of successful of iDT applications.

As future work, it is necessary to make other case studies with different iDT applications in order to refine the set of 14 usability heuristics proposed. The performance of other heuristic evaluations will allow obtaining an important feedback to refine the set of heuristics and associated checklists.

\section{ACKNOWLEDGMENT}

This work has been supported by the IDIS research group of the Universidad del Cauca-Colombia, and by the UseCV research group in Human-Computer Interaction of the Pontificia Universidad Católica de Valparaíso-Chile. This work has been funded by the projects: "Servicios de T-Learning para el soporte de una comunidad académica virtual", Cod 110348925425 , funded by COLCIENCIAS and SENA, the project: "Lineamientos de usabilidad para el diseño de aplicaciones de Televisión Digital Interactiva", code 3583 of Vicerrectoría de Investigaciones of the Universidad del Cauca. In addition, this work has been funded by the "Programa Nacional para Estudios de Doctorado en Colombia Año 2011, de COLCIENCIAS".

\section{REFERENCES}

[1] F. Bellotti, S. Vrochidis, E. Parissi, P. Lhoas, D. Mathevon, M. Pellegrino, G. Bo and I. Kompatsiaris. "A T-learning Courses Development and Presentation Framework". IEEE Multidisciplinary Engineering Education Magazine. Vol. 3, pp. 69-76. 2008.

[2] D. Geerts and D. De Grooff. "Supporting the social uses of television: sociability heuristics for social TV". Computer Human Interaction (CHI '09). 2009.

[3] C.A. Collazos, J. Arciniegas, V.M. Mondragón, and X. Garcia. "Directrices de Diseño y evaluación de la Televisión interactiva desde una perspectiva de Usabilidad". Interacción 2008. Albacete, España. 2008.
[4] R. Otaiza, C. Rusu and S. Roncagliolo. "Evaluating the usability of transactional Web Sites". Third International Conference on Advances in Computer-Human Interactions (ACHI'10). Saint Maarten, Netherlands Antilles. 2010.

[5] C. Wiberg, K. Jegers and H. Desurvire. "How Applicable is Your Evaluation MethodsReally? Analysis and redesign of Evaluation Methods for Fun and Entertainment". Second International Conference on Advances in Computer-Human Interactions (ACHI 2009). Cancun, Mexico. 2009.

[6] International Standard ISO 9241. "Ergonomic requirements for office work with visual display terminals". 1993.

[7] H. Sharp, Y. Rogers and J. Preece. "Interaction Design Beyond Human Computer Interaction". Wiley, John \& Sons Incorporated. Second Ed. 2007. ISBN: 0470018666.

[8] J. Nielsen. "Usability engineering". Morgan Kaufmann. 1993. ISBN: 0-12-518406-9

[9] J. Nielsen. "Ten Usability Heuristics". Fecha de consulta: 12/07/2011. URL: http://www. useit.com/papers/heuristic/heuristic_list.html

[10] A. Solano, C. Rusu, C. Collazos, S. Roncagliolo, J.L. Arciniegas and V. Rusu. "Usability Heuristics for Interactive Digital Television". Third International Conference on Advances in Future Internet (AFIN 2011). Nice/Saint Laurent du Var, France. 2011.

[11] C. Rusu, S. Roncagliolo, V. Rusu and C. Collazos. "A Methodology to Establish Usability Heuristics". Fourth International Conference on Advances in ComputerHuman Interactions (ACHI 2011). Gosier, Guadeloupe, France. 2011.

[12] C. Collazos, C. Rusu, J. Arciniegas and S. Roncagliolo. "Designing and Evaluating Interactive Television from a Usability Perspective". International Conference on Advances in Computer-Human Interactions (ACHI 2009). Cancún, México. 2009.

[13] Proyecto ST-CAV, Servicios de T-Learning para el soporte de una Comunidad Académica Virtual. Fecha de consulta: 26 de marzo de 2011. URL: http://www.unicauca.edu.co/stcav/

[14] Estándar DVB (Digital Video Broadcasting). Fecha de consulta. 2 de abril de 2011. URL: http://www.dvb.org/ 
[15] G. Chanchí, E. Gabriel, W.Y. Campo, J.P. Amaya y J.L. Arciniegas. "Esquema de servicios para Televisión Digital Interactiva, basados en el protocolo REST-JSON". Cuadernos de Informática. Vol. 6, pp. 233240. 2011.

[16] Comisión Nacional de Televisión. Fecha de consulta: 2 de abril de 2011. URL: http:// www.cntv.org.co/cntv_bop/
[17] MHP (Multimedia Home Platform). Fecha de consulta: 2 de abril de 2011. URL: http:// www.mhp.org/

[18] Televisión Digital Terrestre. Fecha de consulta: 4 de abril de 2011. URL: http:// www.televisiondigital.es/Terrestre/Que/ Paginas/Que.aspx

[19] Televisión Digital Terrestre. Fecha de consulta: 6 de abril de 2011. URL: http:// www.tdtandalucia.es/htmlPaginado.html 